\title{
Distribution and release of epidermal growth factor in man
}

\author{
J W KONTUREK, W BIELANSKI, S J KONTUREK, J BOGDAL, AND \\ J OLEKSY
}

From the Institute of Physiology, Academy of Medicine, Krakow, Poland

\begin{abstract}
SUMMARY Epidermal growth factor (EGF) is localised in man to salivary and Brunner's glands. It is present in large concentrations in saliva and duodenal contents but the mechanisms of its release have been little studied. This study carried out on four groups of healthy subjects was designed to determine the distribution and the release of immunoreactive EGF (IR-EGF) in salivary, gastric, duodenal, and pancreatic secretions. Under basal conditions, the concentrations of IR-EGF in salivary, gastric, duodenal and pancreatic secretions were; $2 \cdot 7(0 \cdot 4), 0 \cdot 42(0 \cdot 12), 21(5)$ and $8 \cdot 5(1 \cdot 2)$ $\mathrm{ng} / \mathrm{ml}$, respectively. Chewing of Parafilm* significantly increased salivary but not gastric or duodenal EGF output while atropinisation led to the reduction in basal salivary and duodenal EGF output without affecting the increment in EGF release induced by chewing. Cigarette smoking caused a marked reduction in basal salivary and duodenal EGF output. Infusion of pentagastrin increased salivary and duodenal EGF output and this was blocked by the addition of somatostatin. Injection of secretin lead to an increase in pancreatic output of EGF. We conclude that in man the major sources of EGF are salivary glands, duodenum, and pancreas and that the release of EGF remains under neurohormonal control.
\end{abstract}

Epidermal growth factor (EGF) originally isolated by Cohen' from the mouse submaxillary glands is a 53 amino acid peptide structurally resembling urogastrone, another peptide isolated from urine. Urogastrone was discovered after the observation that the extracts of urine from pregnant women had beneficial effect on healing of chronic ulcers in MannWilliamson dogs. ${ }^{3}$

Studies on animals showed that EGF, like urogastrone, displays many kinds of biological effects including stimulation of proliferation and differentiation of epithelial and non-epithelial tissues ${ }^{2+}$, stimulation of DNA synthesis ${ }^{4}$ through increasing ornithine decarboxylase activity, ${ }^{5}$ protection of the gastroduodenal mucosa against various irritants, ${ }^{7}$ enhancement of healing of chronic gastroduodenal ulceration $^{\text {" }}$ and inhibition of gastric acid secretion." Epidermal growth factor has been reported to be

Address for correspondence: Prof Dr S J Konturek. Institute of Physiology, 31-5.31 Krakow ul. Grzegorzecka I6. Poland.

Accepted for publication 24 January 1989.

*(plastic film which can be chewed to stimulate salivary secretion) present in human saliva, urine and milk ${ }^{112}$ and to be localised to the submandibular glands, Brunner's glands in the duodenum and the Paneth cells of the small intestine. ${ }^{1314}$ Studies on the distribution of EGF in human gastrointestinal tract have, however, been limited mainly to immunocytochemistry and little information is available regarding the distribution and the release of EGF under various physiological conditions. This study was undertaken to compare the release of immunoreactive EGF (IR-EGF) into the salivary, gastric, duodenal and pancreatic secretions under basal conditions and after neurohormonal stimulation and smoking in healthy subjects.

\section{Methods}

SUBJECTS

Male volunteers, aged between 20-24 years (mean age 22) and weighing between $68-77 \mathrm{~kg}$ (mean weight $74 \mathrm{~kg}$ ) entered the study after giving informed consent. All subjects were in good health and without gastro-intestinal disorders. Gastroscopy carried out one week before the start of the study revealed no 
abnormalities or peptic ulceration. None of the subjects showed any abnormalities in the orodental, oropharyngeal and salivary gland areas. The study was approved by the Institutional Human Research Review Committee.

\section{I:XPI:RIMINTAL DESIGN}

Several series of experiments were carried out on four groups (group A, B, C and D) of subjects with five to seven day intervals between tests. Ten subjects (group A) underwent studies with basal secretion and Parafilm chewing without or with atropinisation; 10 subjects (group B) were used for studies with pentagastrin and somatostatin, 10 subjects (group C) were used for studies with cigarette smoking and six others (group D) were used to obtain pure pancreatic juice before and after secretin administration.

On the morning after $12 \mathrm{~h}$ fasting period, all subjects refrained from smoking and did not use tooth paste. Double lumen gastroduodenal Dreiling tube with endotracheal cuff was inserted and positioned under fluoroscopic control with the cuff inflated just distally to the pylorus to prevent any

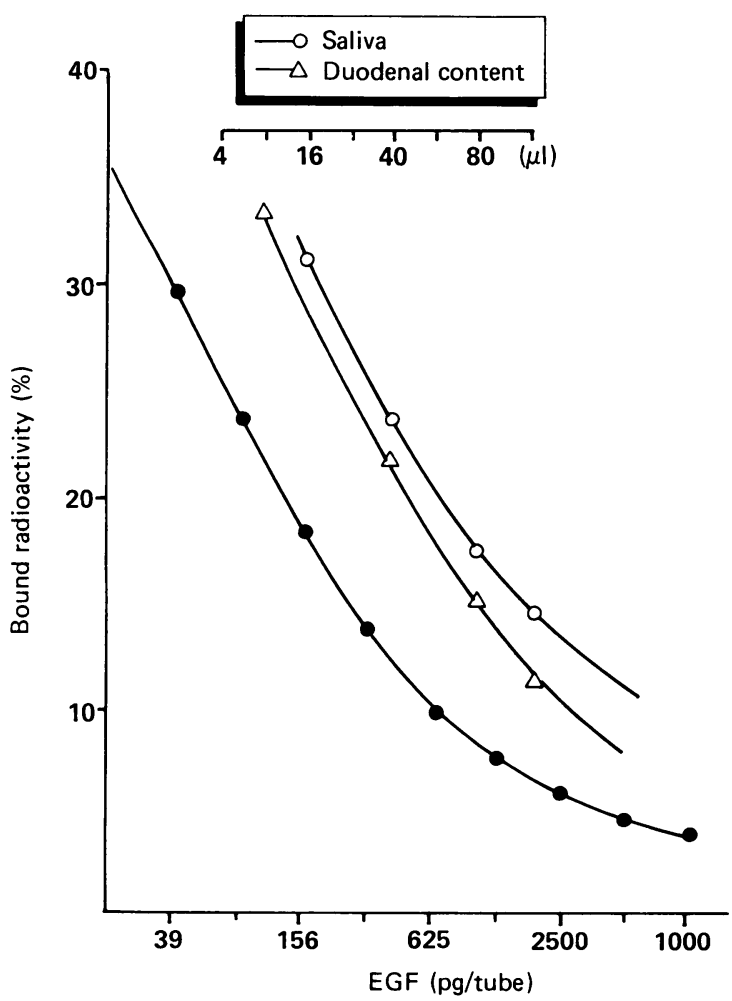

Fig. 1 Standard calibration curves for human EGF radioimmunoassay using (•) Standard human EGF, (o) saliva and $(\triangle)$ duodenal secretion. escape of gastric juice into the duodenum or any reflux of the duodenal content into the stomach as previously described. ${ }^{15}$ Subjects were instructed not to swallow throughout the study and saliva, gastric juice and duodenal contents were aspirated and collected in 15 min aliquots. All samples were kept on ice, their volume was measured and 1-2 $\mathrm{ml}$ aliquots were taken into plastic tubes with Trasylol (50) IU/I $\mathrm{ml}$ ), adjusted to $\mathrm{pH} 7 \cdot()$, centrifuged and supernatant frozen at $-20{ }^{\circ} \mathrm{C}$ until radioimmunoassay of EGF. In addition, the amylase concentration in the saliva, acid concentration in the gastric juice and amylase concentration in the duodenal aspirates were determined as described before ${ }^{1516}$ and expressed in outputs per $30 \mathrm{~min}$.

In tests on group A subjects, the salivary gastric and duodenal secretions were collected for a one hour period and then 15 min Parafilm chewing was carried out followed by additional one hour collection period. These tests were repeated after iv injection of atropine (10 $\mu \mathrm{g} / \mathrm{kg}$ ) after $30 \mathrm{~min}$ of basal collection.

In tests of group B subjects, the saliva gastric and duodenal secretions were collected for $30 \mathrm{~min}$ and then pentagastrin $(2 \mu \mathrm{g} / \mathrm{kg} / \mathrm{h})$ was infused for two $\mathrm{h}$. After one hour pentagastrin administration, somatostatin $(2.5 \mu \mathrm{g} / \mathrm{kg} / \mathrm{h})$ was added to iv infusion for the period of one hour. In control tests, pentagastrin alone without somatostatin was infused for a two hour period.

In tests on group $\mathrm{C}$ subjects, basal collection of the salivary gastric and duodenal secretions was obtained for one hour and then one cigarette was smoked during each $30 \mathrm{~min}$ period while the secretory collection was continued for next one hour period.

In 10 subjects of group $D$, pure pancreatic juice was obtained by endoscopic cannulation of the papilla of Vater. A side viewing duodenoscope, Olympus model JF-B, was used, through which a sterile Teflon cannula was passed (external diameter $1.5 \mathrm{~mm}$ ). Only subjects with a normal retrograde pancreatogram without a separate opening of the duct of Santorini into the duodenum, and with a pancreatic duct system not communicating with the common duct were included into the study. Consequently, a contamination of pancreatic juice with bile was avoided. Tests were done in the early morning after an overnight fast, after local application of $20 \%$ benzocaine (Hurricaine, Bentlich Pharmaceutical, Chicago, III.) on the oropharyngeal mucosa. Subjects were allowed to be on the left side to facilitate pooling of the gastric contents in the body of the stomach. Gastric juice was continuously aspirated during endoscopy through an additional tube with a vacuum pump at a negative pressure of about $20 \mathrm{~mm}$ $\mathrm{Hg}$. Duodenal content was first aspirated through the Teflon cannula, which was then inserted into the 
papilla to a depth of about $2 \mathrm{~cm}$. Pure pancreatic juice was collected during $10 \mathrm{~min}$ before and $10 \mathrm{~min}$ after iv injection of $0.3 \mu \mathrm{g} / \mathrm{kg}$ of synthetic secretin (gift of Prof E Wunsch, Max Planck Institute, Munchen, Germany). Pure pancreatic juice were collected at five to $10 \mathrm{~min}$ aliquots and the samples frozen at $-20{ }^{\circ} \mathrm{C}$ for RIA of EGF.

\section{ASSAYS}

IR-EGF concentrations were measured in samples of saliva, gastric juice, duodenal aspirate and pancreatic juice in the tests on groups A, B, C and D. Radioimmunoassay of EGF was performed using the EGF antiserum (gift of Dr H Gregory, ICI, Alderley Park, UK) raised in rabbits against human EGF and employed in this assay in final dilution of $1: 120000$ (Fig. 1). It showed no cross-reactivity with structurally related rat EGF or with other gut peptides such as gastrin, CCK, secretin, GIP or PP. Iodinated [3-(125)iodotyrosyl] peptide (purchased from Amersham, UK) and calibration standards were human EGF. The assay buffer was $0 \cdot() 4 \mathrm{M}$ phosphate buffer, $\mathrm{pH} 7.2$ with $0.5 \%$ BSA. The separation of the antibody bound and free fractions of EGF was achieved using dextran coated charcoal. Each sample was assayed in duplicate. A typical standard curve for authentic human EGF and serial dilution curves for saliva and duodenal secretion prepared in this assay is shown in Figure 1. Detection limit of the assay was about $0.25 \mathrm{ng} / \mathrm{ml}$, and intra-assay and interassay precisions were about $10 \%$ and $14 \%$, respectively.

\section{STATISTICAI. ANALYSIS}

Results are quoted as means (SEM). Statistical analysis of the differences in EGF concentrations and outputs between means of basal periods and these obtained after chewing or pentagastrin infusion and between corresponding control studies and those after administration of somatostatin, atropine or smoking was carried out using Student's $t$ test for unpaired values or many sample one-way analysis of variance and Duncan's multiple range test. The difference between means were considered significant at $\mathrm{p}<0 \cdot() 5$.

\section{Results}

Figure 2 shows the outputs of IR-EGF in saliva, gastric juice and duodenal secretion under basal conditions and after chewing of Parafilm in subjects of group A. Basal EGF outputs in saliva averaged from 20 to $35 \mathrm{ng} / 15 \mathrm{~min}$ and its concentration was about $2.7(0.4) \mathrm{ng} / \mathrm{ml}$. Chewing of Parafilm caused significant increase in EGF output that was observed only during $15 \mathrm{~min}$ period of chewing and accompanied by a significant increase in the volume of
Table 1 Volume of saliva and the concentrations of EGF in saliva in tests with parafilm chewing in subjects of group $A$. Means (SEM) of 10 tests on 10 subjects

\begin{tabular}{|c|c|c|c|c|}
\hline & $\begin{array}{l}\text { Volume } \\
\text { Che'wing } \\
\text { Alone }\end{array}$ & $\begin{array}{l}\text { (ml/l.5 min) } \\
\text { Che'wing } \\
\text { +atropine }\end{array}$ & $\begin{array}{l}\text { IR-EGF } \\
\text { Che'wing } \\
\text { alone' }\end{array}$ & $\begin{array}{l}\text { (ng/ml) } \\
\text { Chewing } \\
+ \text { atropine }\end{array}$ \\
\hline \multicolumn{5}{|c|}{$1.5-\mathrm{min}$ periods } \\
\hline lst & $15 \cdot 8(4.8)$ & $16 \cdot 2(3.9)$ & $2 \cdot 9(() \cdot 6)$ & $3.2(0.7)$ \\
\hline 2nd & $14 \cdot 8(3.8)$ & $12 \cdot 0(2 \cdot 7)$ & $2.5(0 \cdot 4)$ & $2 \cdot 8(0 \cdot 4)$ \\
\hline $3 \mathrm{rd}$ & $12 \cdot 3(2 \cdot 6)$ & $7 \cdot(1)(1 \cdot 1) \div \div$ & $2 \cdot 3(0 \cdot 8)$ & $1.9(0.3) \dagger$ \\
\hline 4 th & $12 \cdot 3(2 \cdot 5)$ & $4.5(0.4) \div$ & $2 \cdot 6(0 \cdot 6)$ & $2 \cdot 4(0 \cdot 4)$ \\
\hline $5 \mathrm{th}^{*}$ & $29 \cdot()(3.6)$ & $8 \cdot 8(2 \cdot 6) \div$ & $1.6(0.7)$ & $3.4(0.8)$ \\
\hline 6th & $16 \cdot 1(3 \cdot())$ & $5.9(1 \cdot 1) \div$ & $1 \cdot 8(() \cdot 6)$ & $3 \cdot 6(0 \cdot 8)$ \\
\hline $7 \mathrm{th}$ & $15 \cdot 5(3.3)$ & $4 \cdot 1(1 \cdot(0) \div$ & $1 \cdot 4(() \cdot 5)$ & $4.2(1.6)$ \\
\hline Sth & $14 \cdot 8(3 \cdot 6)$ & $3.9(1.4) \div$ & $1 \cdot 6((1) \cdot 4)$ & $5.1(1.7)$ \\
\hline 9th & $15 \cdot 7(3.4)$ & $4.2(1.8) \div$ & $1 \cdot 7(0 \cdot 4)$ & $4.6(1.7)$ \\
\hline
\end{tabular}

Period when parafilm-chewing was performed: tperiod when atropine was injected: tsignificant $(p<0 \cdot(05)$ decrease below the value obtained in control tests with atropine.

saliva from basal value of about $12 \cdot 5(2 \cdot 6) \mathrm{ml} / 15 \mathrm{~min}$ to $29 \cdot 0(3 \cdot 6) \mathrm{ml} / 15 \mathrm{~min}$ (Table 1). EGF concentration during chewing tended to decrease but it was not significant.

The concentration $(0 \cdot 42(0 \cdot 12) \mathrm{ng} / \mathrm{ml})$ and the output $(5.4(1.2) \mathrm{ng} / 15 \mathrm{~min})$ of EGF in gastric juice were several times smaller than in saliva (Table 1). Chewing of Parafilm, pentagastrin or smoking failed to cause any alteration of these values in gastric juice suggesting that EGF in the stomach may be produced in negligible amounts or may originate from other sources such as salivary glands or duodenum. The concentrations and outputs of EGF in the duodenal contents were, respectively, about five and two times higher than in saliva. Chewing tended to increase duodenal EGF outputs but this was not statistically significant.

Injection of atropine $(10 \mu \mathrm{g} / \mathrm{kg})$ caused significant reduction in basal salivary and duodenal but not gastric outputs of EGF. This reduction was due to the decrease in the volume of saliva and duodenal contents (Table 1). Chewing in atropinised subjects resulted in the increment in salivary EGF outputs but no changes in EGF outputs were observed in gastric or duodenal contents (Fig. 2).

Chewing significantly increased salivary amylase outputs and this effect was almost completely abolished by atropine. No significant alteration in gastric acid or duodenal amylase outputs were observed during chewing but atropine caused significant reduction in gastric acid and duodenal amylase secretion (Table 2).

After infusion of pentagastrin (at a dose which caused maximal gastric acid output) significant and sustained increase in salivary and duodenal but not gastric EGF outputs were observed (Fig. 3). This 


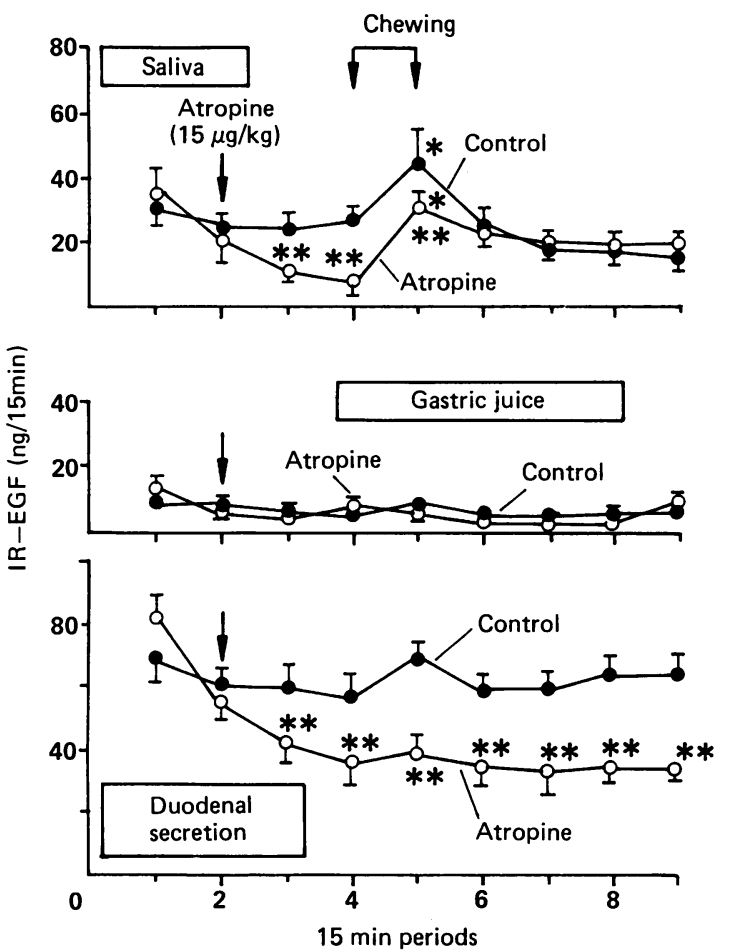

Fig. 2 EGF outputs in saliva, gastric juice and duodenal secretion under basal conditions and after parafilm chewing without and with administration of atropine. Means (SEM) of 10 tests in 10 healthy subjects. ${ }^{*}$ Indicates significant increase above the basal value and ${ }^{* *}$ indicates significant decrease below the value obtained in tests without atropine.

increase in EGF secretion was mainly caused by the rise in the volume of salivary and duodenal secretions. Somatostatin infused at a dose $(2.5 \mu \mathrm{g} / \mathrm{kg} / \mathrm{h})$ which strongly inhibited gastric acid response to pentagastrin, resulted in the decrease in salivary and duodenal secretions to the basal (prepentagastrin) level. No change in gastric EGF outputs were observed in tests with pentagastrin and somatostatin infusion. Pentagastrin infusion induced a significant increase in salivary and duodenal amylase outputs and in gastric acid outputs. Addition of somatostatin resulted in significant decrease in all these secretory parameters to the basal value (Table 2).

Smoking one cigarette per $30 \mathrm{~min}$ resulted in a significant reduction in EGF concentrations and outputs both in saliva and duodenal contents (Fig. 4). This reduction was pronounced and observed throughout the period of smoking.

Table 3 shows the concentrations and outputs of EGF in pancreatic juice obtained during endoscopic cannulation of pancreatic duct before and after injection of secretin. The concentration of EGF in
Table 2 Salivary and duodenal outputs of amylase and gastric outputs of $\mathrm{HCl}$ in tests with parafilm chewing without and with administration of atropine in subjects of group $A$ and with pentagastrin infusion without and with somatostatin in subjects of group $B$

\begin{tabular}{|c|c|c|c|}
\hline Type of test & $\begin{array}{l}\text { Salivary amylase } \\
\text { (U1,30 min) }\end{array}$ & $\begin{array}{l}\text { Gastric } H C l \\
\text { mmol/30 min }\end{array}$ & $\begin{array}{l}\text { Duodenal } \\
\text { amylase' } \\
\text { (Ui,30 min }\end{array}$ \\
\hline Basal & $52(8)$ & $(0.74(0.22)$ & $18(3)$ \\
\hline Chewing & $129(14)^{*}$ & $1 \cdot(12(0.45)$ & $22(4)$ \\
\hline $\begin{array}{l}\text { Chewing } \\
\text { +atropine }\end{array}$ & $31(4) \dagger$ & $0.26(0 \cdot 10)^{\dagger}$ & $12(2) \div$ \\
\hline Pentagastrin & $106(12)^{*}$ & $9 \cdot 28(1 \cdot+8)^{*}$ & $38(4)^{*}$ \\
\hline Pentagastrin & $44(6)^{\dagger}$ & $3.04(1.18)^{\dagger}$ & $2+(2) \div$ \\
\hline
\end{tabular}

*Significant $(\mathrm{p}<0.05)$ increase above basal level: + Significant $(p<0.05)$ decrease below the value obtained with chewing alone or pentagastrin alone.

pure pancreatic juice before secretin injection was about $8.5(1.2) \mathrm{ng} / \mathrm{ml}$ and after secretin it tended to decrease to about $6 \cdot 2(1 \cdot 6) \mathrm{ng} / \mathrm{ml}$. The outputs of EGF in the pancreatic secretion after secretin administration increased several fold but this was mainly the result of the increase in the pancreatic volume flow.

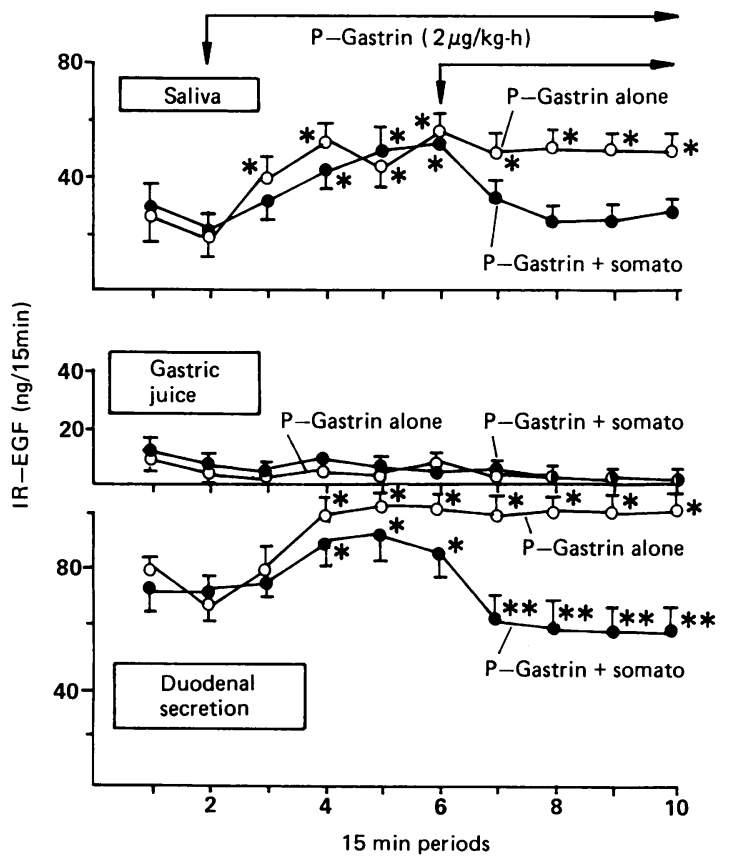

Fig. 3 Effects of pentagastrin alone and combined with somatostatin on salivary, gastric and duodenal EGF outputs. Mean (SEM) of 10 tests on 10 healthy subjects. *Indicates significant increase above basal values and **indicate significant decrease below the value obtained with pentagastrin alone. 

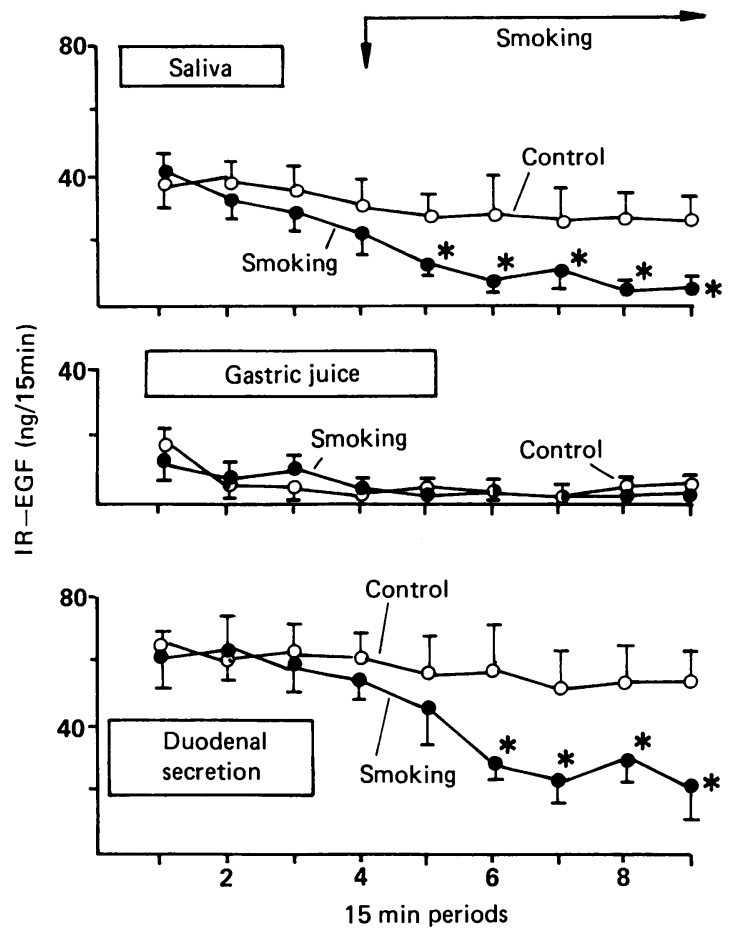

Fig. 4 Effect of smoking on EGF outputs in sulivary, gastric and duodenal secretions. *Indicates significant decrease below the control value obtained in tests without smoking. Mean (SEM) of 10 tests on 10 healthy subjects.

\section{Discussion}

This study provides evidence that as well as the salivary glands, the duodenal mucosa and the pancreas, are rich sources of IR-EGF in human gastrointestinal tract. Previous studies showed that EGF is localised mainly to salivary glands and Brunner's glands in the duodenum ${ }^{131+}$ and secreted into saliva." 12

Our study shows for the first time that simple chewing, activating stimulatory mechanism of salivary flow, increases also the output of IR-EGF in

Table 3 Concentration and output of EGF in pure pancreatic juice obtained by endoscopic cannulation of pancreatic duct in subjects of group D. Means (SEM) of 10 tests on 10 subjects.

\begin{tabular}{lclc}
\hline & $\begin{array}{l}\text { Volume of juice } \\
(\mathrm{ml} / 10 \mathrm{~min})\end{array}$ & $\begin{array}{l}\text { EGF concentration Output } \\
(\mathrm{ng} / \mathrm{ml})\end{array}$ & $\begin{array}{l}\text { Ong } \\
(\mathrm{ng} / 10 \mathrm{~min})\end{array}$ \\
\hline Basal & $2 \cdot 1(0 \cdot 7)$ & $8 \cdot 5(1 \cdot 2)$ & $18 \cdot 4(2 \cdot 6)$ \\
Secretin & $19 \cdot 2(3 \cdot 6)^{*}$ & $6 \cdot 2(1.6)$ & $117 \cdot 8(14 \cdot 9)^{*}$ \\
\hline
\end{tabular}

*Significant $(\mathrm{p}<0.05)$ increase above the basal value. the saliva. This is probably caused, in part, by 'washout' of the peptide from the salivary glands because of a marked increase in the volume flow but the excitation of neural mechanism cannot be excluded because atropinisation which reduced basal salivary volume flow and basal EGF output, failed to affect an increment in EGF secretion induced by chewing. It is of interest that chewing caused also significant increase in salivary amylase output. Atropine completely prevented the amylase response to chewing suggesting that the secretion of this enzyme is under cholinergic control. Previous studies on salivary secretion of EGF in rats suggested that activation of cholinergic pathway increased EGF release, whereas stimulation of alpha-adrenergic pathway inhibited this release. ${ }^{17}$ It has been proposed that VIP and acetylcholine coexist in the same nerve terminals and cooperate in the stimulation of the release of EGF." ${ }^{\text {F }}$ Further studies are needed to determine whether the increment in salivary EGF release observed after chewing in subjects without or with atropinisation is mediated by non-cholinergic and VIP-ergic (atropine-resistant) pathways.

Chewing did not influence the release of EGF in the duodenum but the hormonal stimulation with pentagastrin was accompanied by a significant increase in EGF relcase both in the saliva and the duodenal secretion. This hormonal stimulation was sensitive to somatostatin which almost completely abolished pentagastrin induced increase in salivary and duodenal EGF. A previous study in man has revealed that pentagastrin stimulates salivary secretion of amylase and that simultaneous administration of somatostatin blocks the effect of pentagastrin on salivary flow but did not reduce the amylase concentration. ${ }^{19}$ Our results with salivary amylase secretion in these tests were similar and they suggest that the mechanism exerted by pentagastrin and somatostatin on EGF release into saliva is different from that involved in amylase secretion. It is of interest that pentagastrin caused also a marked increase in the EGF in duodenum and somatostatin blocked this effect. This suggests that the control of salivary and duodenal EGF secretion may be similar. This is the first finding suggesting the implication of a hormonal mechanism in the release of salivary and duodenal EGF.

Pentagastrin was also potent stimulant of salivary and duodenal amylase outputs and of gastric acid secretion. These effects were strongly reduced by the addition of somatostatin to pentagastrin infusion as described before."

Smoking resulted in a significant decrease in EGF outputs both in salivary and duodenal secretions. As smoking is known to delay the healing of gastroduodenal ulcerations in man, it remains to be clarified 
whether the deficiency of EGF in the gastrointestinal tract of smokers contributes to this effect. It is of interest that the acute phase of peptic ulcerations was accompanied by significant reduction in salivary EGF outputs suggesting that EGF may be implicated in the pathogenesis of peptic ulcerations."

The major finding of this study is the discovery of high concentration of IR-EGF in duodenal and pancreatic secretion. This duodenal IR-EGF immunoreactivity might originate from the Brunner's glands, as suggested before, ${ }^{1: 1+}$ as well as from the pancreas. Previous studies on animals showed that the pancreas contains as high a concentration of EGF as salivary tissue.".$^{2 !}$ It is likely, therefore, that previously reported" and presently observed high EGF content in the duodenum originates, at least in part, from the pancreas. Our finding of high concentration of IR-EGF in the pancreatic juice collected directly from the pancreatic duct provides an evidence that in man, as in animals, the pancreas is a rich source of EGF and that the release of EGF is stimulated by secretion. The rise in pancreatic EGF output after secretin injection was mainly the result of the increase in pancreatic volume flow and probably represented the 'washout' of the peptide from the pancreas. The role of pancreatic EGF is unknown but previous studies showed that this peptide may contribute to the stimulation of pancreatic secretion ${ }^{13}$ and tissue growth. ${ }^{+3:+4}$ Whether EGF secreted in the pancreatic juice in large amounts has any protective, ulcer healing or growth promoting action on the duodenal mucosa is unknown but previous observations of increased production of duodenal ulcerations after diversion of pancreatic juice from the duodenum ${ }^{25}$ suggest that pancreatic EGF may play an important role in the prevention or healing of duodenal ulcerations.

\section{References}

1 Cohen S. Isolation of a mouse submaxillary gland protein accelerating incisor eruption and eyelid opening in the new-born animal. J Biol Chem 1962: 237: 1555-62.

2 Gregory $\mathrm{H}$. Isolation and structure of urogastrone and its relationship to epidermal growth factor. Nature 1975; 257: 325-7.

3 Sandweiss DJ, Friedman MHF. Is the beneficial effect of urine extracts on $\mathrm{M}-\mathrm{W}$ ulcers due to the gastric secretory depressant in urine? Am J Dig Dis 1942: 9: 166-9.

4 Dembinski A. Gregory H, Konturek SJ, Polanski M. Trophic action of epidermal growth factor on the pancreas and gastroduodenal mucosa in rats. $J$ Physiol (Lond) 1982; 325: 35-42.

5 Feldman EJ, Aures D. Grossman MI. Epidermal growth factor stimulates ornithine decarboxylase activity in the digestive tract of mouse. Proc Soc Exp Biol Med 1987; 159: $400-2$.
6 Konturck SJ. Radecki T, Brzozowski T. et al. Gastric cytoprotection by epidermal growth factor. Role of endogenous prostaglandins and DNA synthesis. (jastroenterology 1981: 81: 438-43.

7 Skov Olsen P. Poulsen SS. Kirkegaard P. Nexo E. Role of submandibular saliva and epidermal growth factor in gastric cytoprotection. Gastroenterology 1984: 87: $103-8$.

8 Skov Olsen P, Poulsen SS, Therkelsen K. Nexo E. Effect of sialoadenectomy and synthetic human urogastrone on healing of chronic gastric ulcers in rats. $G$ itt 1986: 27: 1443-9.

9 Skov Olsen P. Poulsen SS, Therkelsen K. Nexo E. Oral administration of synthetic human urogastrone promotes healing of chronic duodenal ulcers in rats. Gastroenterology 1986; 90: 911-7.

10) Konturek S. Cieszkowski M, Jaworek J, Brzozowski T, Gregory $H$. Effects of epidermal growth factor on gastrointestinal secretion. Am J Physiol 1984; 246: 56()86.

11 Hirata Y, Orth DN. Epidermal grouth factor (urogastrone) in human fluids: size heterogencity. I (lin Endocrinol Metab 1979; 48: 673-9.

12 Gregory H. Walsh S. Hopkins CR. The identification of urogastrone in serum, saliva and gastric juice. Gastroenterology 1979; 77: 313-8.

13 Elder JB. Williams G, Lacy E, Gregory H. Cellular localization of human urogastrone/epidermal growth factor. Nature (Lond) 1978; 271: 466-7.

14 Heitz PhU, Kasper M, Noorden SV, Polak JM. Gregory H. Pearse AGE. Immunohistochemical localization of urogastrone to human duodenal and submandibular glands. Gut 1978; 19:408-13.

15 Konturek SJ, Biernat J, Kwiccien N, Oleksy J. Effect of glucagon on meal-induced gastric secretion in man. Gastroenterology 1975; 68: 448-55.

16 Bernfeld P. Amylases alfa and beta. Methods En-ymol 1955; 5: 139-48.

17 Skov Olsen P. Kirkegaard P. Poulsen SS. Nexo F. Adrenergic effects on exocrine secretion of rat submandibular epidermal growth factor. (jut 1984: 25: 1234-40.

18 Skov Olsen PS, Kirkegaard P. Poulsen SS. Nexo E. Vasoactive intestinal peptide and acetylcholine stimulate exocrine secretion of epidermal growth factor from the rat submandibular gland. Regul Pept 1986: 15: 37-46.

19 Loguercio C. De Sio J. Romano M. Blanco C. Coltori M. Effect of somatostatin on salivary secretion in man. Digestion 1987; 38: 91-5.

20 Ohmura E, Emoto N, Tsushima T, et al. Salivary immunoreactive human epidermal growth factor (IR-hEGF) in patients with peptic ulcer disease. $J$ Hepato-Gastroenterol 1987; 34: 160-3.

21 Yip TT, Tam YY. Keung WM, Xin JX. Kong YC. Studies on shrew (suncus murinus) epidermal growth factor. Acta Endocrinol 1986: 111: 424-32.

22 Kirkegaard P, Olsen PS, Nexo E. Holst JJ, Poulsen SS. Effect of vasoactive intestinal polypeptide and somatostatin on secretion of epidermal growth factor and bicarbonate from Brunner's glands. (jut 1984; 25: 1225-9.

23 Logsdon CD. Williams JA. Epidermal growth factor 
binding and biological effects on mouse pancreatic acini. Gastroenterology 1983; 85: 339-45.

24 Logsdon CD. Stimulation of pancreatic acinar cell growth by CCK, epidermal growth factor, and insulin in vitro. Am J Physiol 1986; 251: 487-94.
25 Konturek SJ, Dubiel J, Gabrys B. Effect of exclusion, acidification and excision of the duodenum on gastric acid secretion and the production of pentagastrininduced peptic ulcers in cats. Gastroenterology 1969; 56: 703-10. 